\title{
Increased NHC Cells in the Peritoneal Cavity of Plasmacytoma Susceptible BALB/c Mouse
}

\author{
Berenice Sánchez-González, ${ }^{1}$ Francisco Javier García-Vázquez, ${ }^{2}$ \\ José Eduardo Farfán-Morales, ${ }^{2}$ and Luis Antonio Jiménez-Zamudio ${ }^{1}$ \\ ${ }^{1}$ Departamento de Inmunología, Laboratorio de Inmunología Clínica, Escuela Nacional de Ciencias Biológicas, \\ Instituto Politécnico Nacional, 11340 Mexico, DF, Mexico \\ ${ }^{2}$ Departamento de Anatomía Patológica, Laboratorio de Patología Molecular, Instituto Nacional de Pediatría, \\ 04530 Mexico, DF, Mexico
}

Correspondence should be addressed to Berenice Sánchez-González; beresang@hotmail.com

Received 27 September 2014; Accepted 5 January 2015

Academic Editor: Madhav Bhatia

Copyright (C) 2015 Berenice Sánchez-González et al. This is an open access article distributed under the Creative Commons Attribution License, which permits unrestricted use, distribution, and reproduction in any medium, provided the original work is properly cited.

\begin{abstract}
$\mathrm{BALB} / \mathrm{c}$ strain mice are unique in that they develop murine plasmacytoma (MPC) as a consequence of the inflammation induced by pristane oil injection in the peritoneal cavity. In this work the Treg, Th17, B1, B2, and NHC lymphocyte populations from the peritoneal environment of BALB/c, the susceptible strain, and C57BL/6 mice, which do not develop MPC after oil treatment, were studied. Both oil-treated strains showed decreased levels of Th17 lymphocytes, no significant variation in Treg lymphocytes, and a drastic decrease of all B lymphocyte populations. However, only oil-induced BALB/c showed increased levels of natural helper cells (NHC) which could be important in the myeloma induction.
\end{abstract}

\section{Introduction}

$\mathrm{BALB} / \mathrm{c}$ mice develop murine plasmacytoma (MPC) upon intraperitoneal administration of pristane, (2,6,10,14-tetramethylpentadecane), a component of mineral oil [1-5]. IL-6, TGF- $\beta 1$, and other factors are required for transformation of B lymphocyte to MPC [6-8]. IL-6 blocks the differentiation of the Treg cells $[9,10]$ which inhibit autoreactive $\mathrm{T}$ cell and modulate immune functions by releasing TGF- $\beta 1$ and IL-10 [11], but it promotes the generation of proinflammatory Th17 cells, characterized by the expression of ROR $\gamma \mathrm{t}$ transcription factor and the production of IL-17, which induces the production of a wide range of proinflammatory cytokines and neutrophil-attracting chemokines [12].

The innate lymphoid cell population which has been called natural helper cells (NHC) for its cytokine profile may also be involved in the inflammatory process [13]. These cells are found in lymphoid clusters surrounded by fatty tissue, which have been called FALCs (of fat-associated lymphoid cluster), and have markers such as c-kit, Sca-1, IL7R, and IL33R [13-17]. NHC are involved in the B1 cells proliferation [13].

The B1 lymphocytes are a B cell subpopulation, markedly different from the usually studied B2. Whereas B2 are CD23 $3^{+}$ and $\mathrm{CD} 43^{-}, \mathrm{B} 1$ cells are $\mathrm{CD} 23^{-}$and $\mathrm{CD} 43^{+}$. B1 cells are further divided into $\mathrm{Bla}\left(\mathrm{CD}^{+}\right)$cells and $\mathrm{Blb}\left(\mathrm{CD}^{-}\right)$. $\mathrm{B} 1$ are self-renewing and are found in the peritoneal and pleural cavities and its main function is the constitutive production of natural IgM antibodies, which provide early protection to a variety of pathogens [18-21]. Bla cells have regulatory properties because their IL-10 production [21-24] and promote expansion of T cells $[25,26]$. However, B1 cells are often autoreactive [18], but it is not well understood how they are regulated to prevent autoimmunity.

The aim of the study was to determine what is it that makes the BALB/c susceptible to the myeloma development as a consequence of the inflammatory response induced by the pristane oil in the peritoneal cavity. 

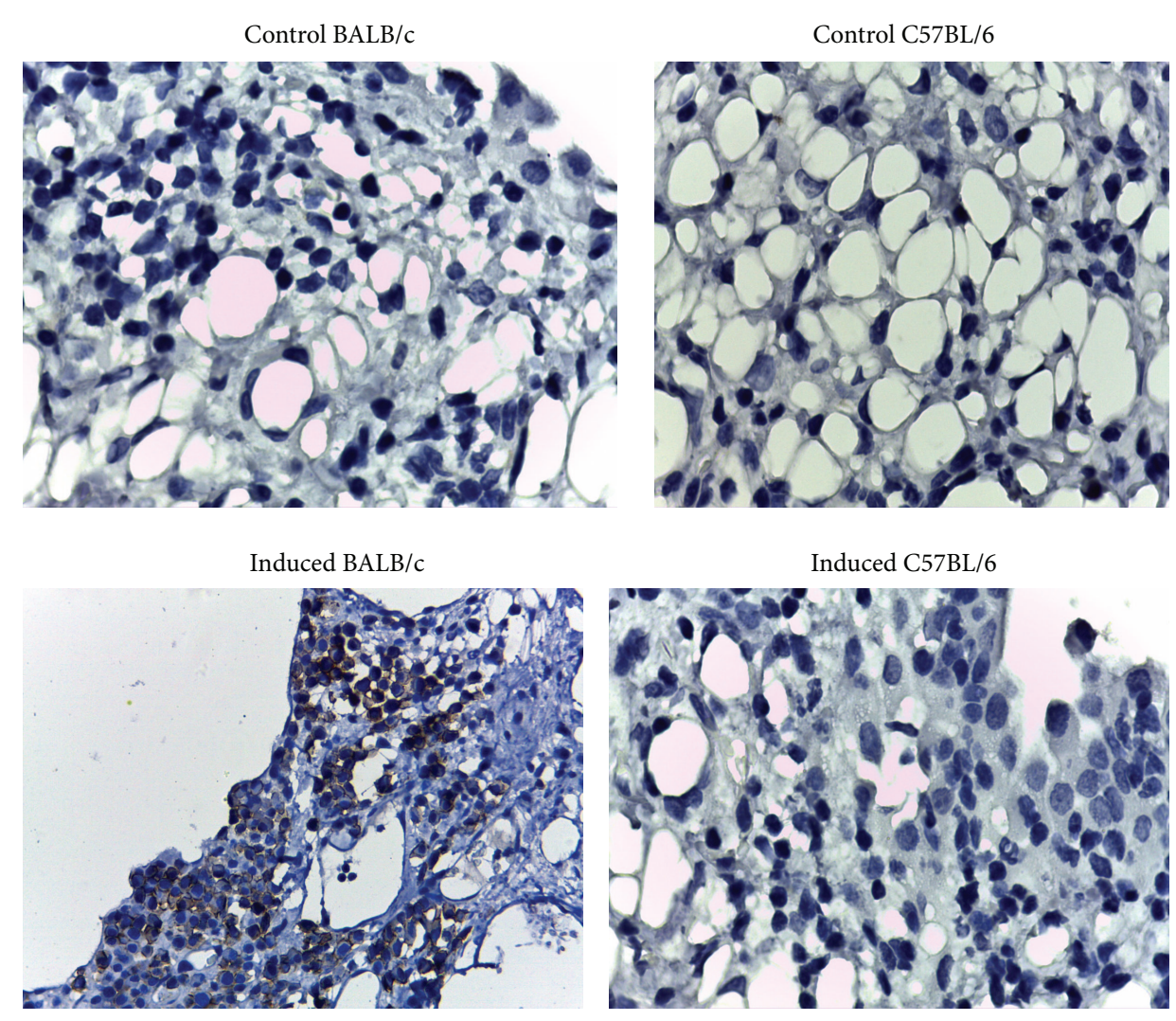

Figure 1: Mesothelial tissue of control and oil-induced mice from both mouse strains at seven months after induction. Only the pristaneinduced $\mathrm{BALB} / \mathrm{c}$ mouse developed malignant plasma cells $\mathrm{CD}_{138^{+}}$(cells with brown tonalities membrane), 40x magnification.

\section{Methods}

2.1. Mice. BALB/cAnNHsd and C57BL/6NHsd female mice, 7-8 weeks old, were purchased from Harlan Laboratories, S.A. de C.V. Mice were handled at all times according to the Official Mexican Standard NOM-062-Z00-1999, technical specifications for production, care and use of laboratory animals. Pristane injections did not require the use of anesthetic, analgesic, or tranquilizer. The intraperitoneal administration of pristane was performed in the animal while always handling it gently but firmly, avoiding the struggle and stress at all times. The method used for euthanasia of mice was exposure to carbon dioxide $\left(\mathrm{CO}_{2}\right)$.

2.2. Oil Induction. Mice were injected intraperitoneally with $500 \mu \mathrm{L}$ pristane (P2870, Sigma-Aldrich), at days 0, 60, and 120. We used the method as described by Potter and Wax, of $1.5 \mathrm{~mL}$ pristane given in $30.5 \mathrm{~mL}$ doses spaced 2 months apart [5].

2.3. Obtention of Peritoneal Content and Mesenteric and Mesothelial Tissues. Seven months after the initial pristane treatment, the oil-treated and control mice of both mouse strains were sacrificed and the peritoneal content was obtained as previously described [27]. A piece of skin was cut into the belly to expose the mesothelium and the peritoneal cavity was washed by introducing $5 \mathrm{~mL}$ of RPMI 1640 medium (31800-022 Gibco). The cavity was vigorously massaged and the content was aspirated using the same syringe. The oil-treated BALB/c mice develop MPC after seven months and in this group the peritoneal content was aspirated directly due to large accumulation of ascitic fluid. From the peritoneal content cells and fluid were separated by centrifugation. Obtention of mesenteric tissue and identification of FALCs regions (fat-associated lymphoid clusters of NHC) with toluidine blue were performed as described [13]. Nevertheless, in oil-treated mice of both strains the FALCs regions were not visibly detectable. Mesenteric and mesothelial tissues were collected in both strains only at seven months after induction and preserved in paraffin blocks $[1,28,29]$.

2.4. Lymphocyte Determination by Flow Cytometry. Cells were determined from the peritoneal content obtained from control and oil-induced mice at seven months. For Th17 determination cells were stimulated during four hours in the presence of $50 \mathrm{ng} / \mathrm{mL}$ of PMA (Phorbol 12-myristate 13-acetate P 8139, Sigma) and $500 \mathrm{ng} / \mathrm{mL}$ of Ionomycin (Ionomycin calcium salt 10634, Sigma-Aldrich). For the last two hours, Brefeldin A (00-4506, eBioscience) and Protein Transport Inhibitor (554724, BD GolgiStop) were added. Treg and Th17 cells were preincubated with Purified Rat Anti 

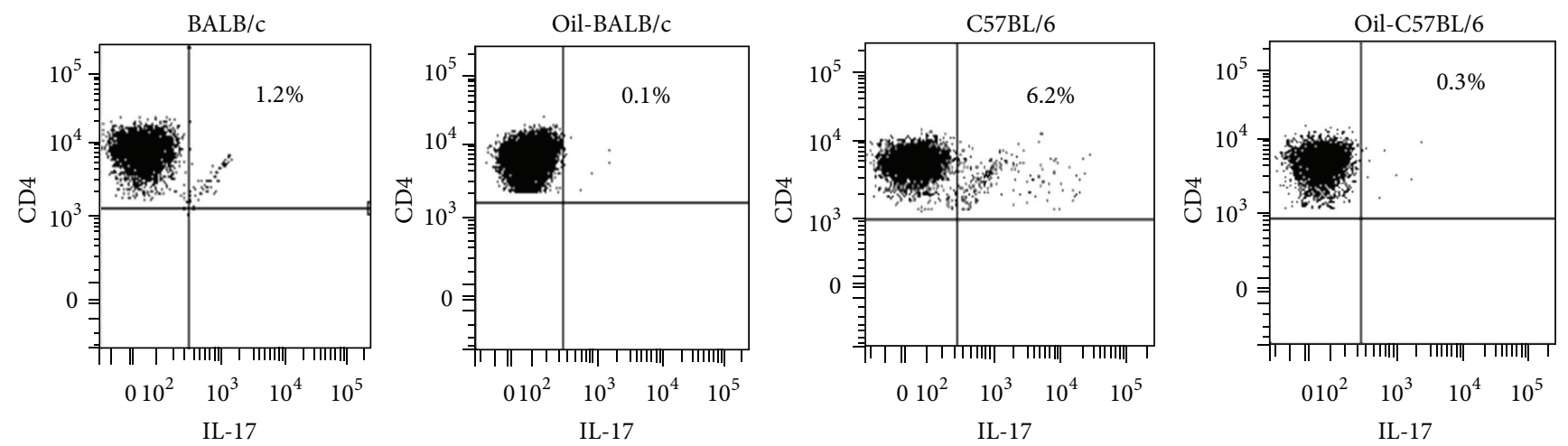

(a)

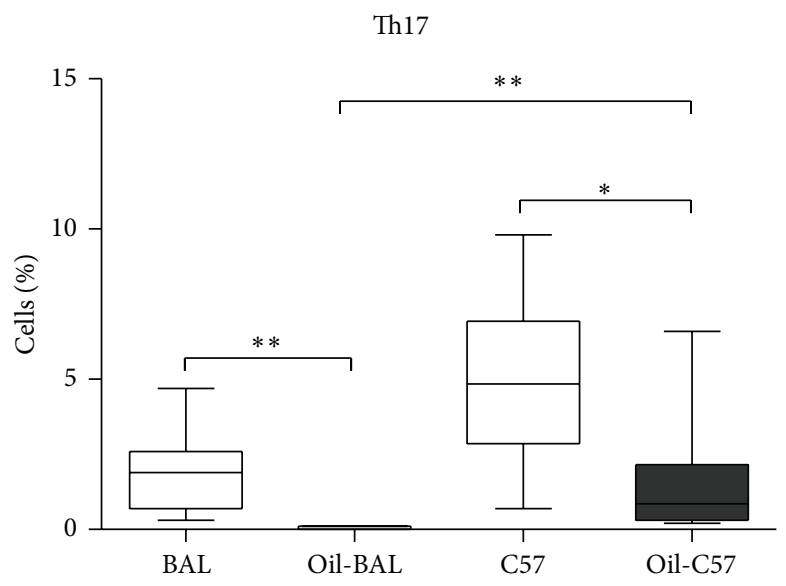

(b)

Figure 2: Th17 cells. (a) Dot plots show percentages of Th17 cells from the peritoneal content from control and oil-induced mice at seven months after induction. The $\mathrm{CD} 4{ }^{+} \mathrm{IL}-17^{+}$cells come from $\mathrm{CD}^{+}$selected from total lymphocyte region. (b) Percentage medians of Th17 without activation in the aforementioned groups of animals $P^{*} \leq 0.05, P^{* *} \leq 0.008(n=5-10)$. Th17 cells of induced animals (oil-induced) of both strains are decreased, but the percentage is higher in the oil-induced C57BL/6 strain compared with oil-induced BALB/c strain.

Mouse CD16/CD32 clone 2.4G2 (553142, BD Pharmingen) to block Fc receptors. Subsequently the extracellular staining was performed in $100 \mu \mathrm{L}$ of PBS-F (PBS/2\% FACS Buffer) and the specific antibodies, for 30 minutes in darkness. For Treg and Thl7 cell identification, PerCP Hamster Anti-Mouse CD3 $\varepsilon$ clone 145-2C11 (553067, BD Pharmingen) and FITC Rat Anti-Mouse CD4 clone RM4-5 (553046, BD Pharmingen) and, for B1 cells, PerCP Rat Anti-Mouse CD5 clone 53-7.3 (553025, BD Pharmingen), FITC Rat Anti-Mouse CD43 clone S7 (553270, BD Pharmingen), PE Rat Anti-Mouse CD11b clone M1/70 (553311, BD Pharmingen), and APC Rat AntiMouse CD19 clone 1D3 (550992, BD Pharmingen) were used. Prior to intracellular staining, Treg and Th17 cells were fixed for 30 minutes at $4^{\circ} \mathrm{C}$ and permeabilized for 30 minutes at $37^{\circ} \mathrm{C}$ both in the dark with Mouse Foxp3 Buffer Set (560409, BD Pharmingen). Intracellular staining of Th17 and Treg cells was performed with the PE Rat Anti-Mouse IL-17A clone TC11-18H10 (559502, BD Pharmingen) and PE Rat Anti-Mouse Foxp3 clone MF23 (560408, BD Pharmingen), respectively, for 30 minutes in a volume of $100 \mu \mathrm{L}$ PBS-F in the dark. Finally, cells were analyzed on the FACSAria cytometer, using the Davia software.
2.5. NHC Cells and Malignant Plasma Cells. Nine-micron sections were cut from the mesenteric and mesothelial tissue preserved in paraffin blocks. Histological sections were subjected to a hydration and unmasking treatment, and specific staining with the corresponding primary and secondary antibody was performed. The primary antibody for the identification of NHC cells was CD117/c-kit clone EP10 (CME 296 AK, Biocare Medical) and Biotin-SP-AffiniPure Goat Anti-Rabbit IgG (111-065-003, Jackson ImmunoResearch) as the secondary antibody. Malignant plasma cells were stained with Purified Rat Anti-Mouse CD138 clone 281-2 (553712, BD Pharmingen) and Peroxidase-AffiniPure Goat Anti-Rat IgG (112-035-062, Jackson ImmunoResearch).

2.6. Cytokines Assay. Cytokines were determined from the peritoneal fluid from both mouse strains, control and oil-induced at seven months, with commercial kits of eBioscience: Mouse IL-6 ELISA Ready- Set-Go (88-7064), Human/Mouse TGF beta 1 ELISA Ready-SET-Go! 2nd Generation (88-8350), Mouse IL-10 ELISA Ready-SET-Go! 2nd Generation (88-7105), Mouse IL-4 ELISA Ready-SETGo! (88-7044), Mouse IL-9 ELISA Ready-SET-Go! 2nd 

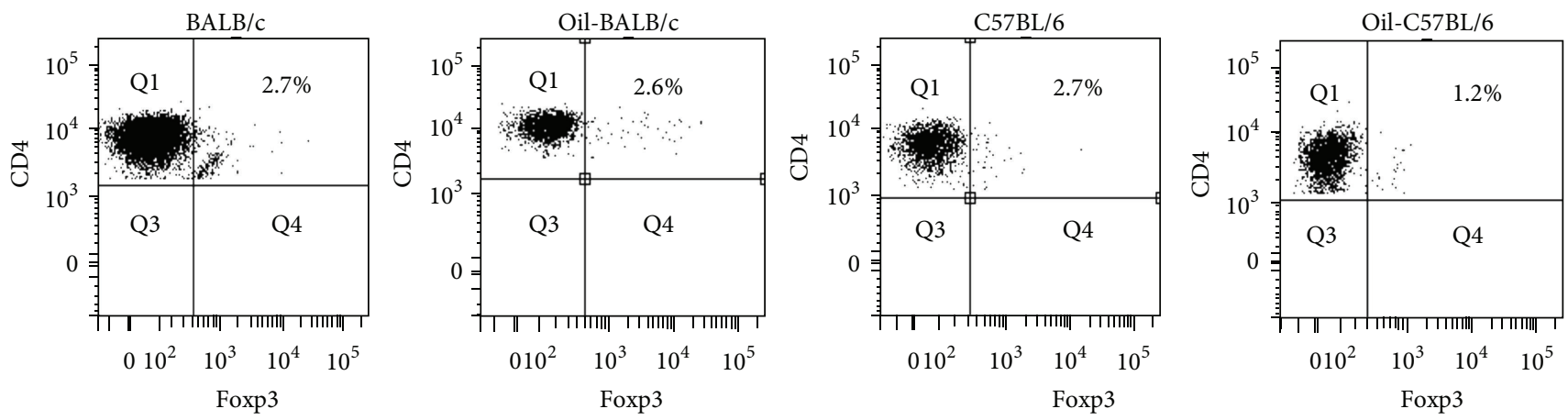

(a)

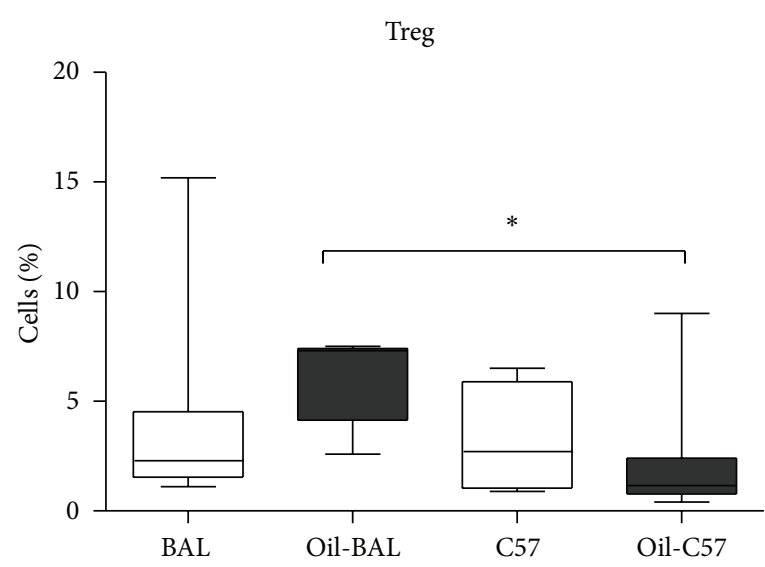

(b)

Figure 3: Treg cells. (a) Dot plots show percentages of Treg cells from the peritoneal content from control and induced mice at seven months after induction. The lymphocytes $\mathrm{CD}^{+}{ }^{+}$Foxp $3^{+}$derived from $\mathrm{CD}^{+}$selected from total lymphocyte region. (b) Percentage medians of Treg in the above groups of animals $P^{*} \leq 0.05, P^{* *} \leq 0.008(n=5-10)$. No changes were observed in Treg when animals were induced. However, the BALB oil-induced mice had a higher percentage of Treg than the C57BL/6 oil-induced mice.

Generation (88-8092), Mouse IL-13 ELISA Ready-SET-Go! (88-7137), Mouse IL-5 ELISA Ready-SET-Go! (88-7054), Mouse IFN gamma ELISA Ready-SET-Go! (88-7314), and Mouse IL-33 ELISA Ready-SET-Go! (88-7333).

2.7. Statistical Analysis. The results of each test are represented by the median of five or more independent experiments. The nonparametric Mann-Whitney $U$ was utilized by GradPad Prisma program for displaying graphics and Sigma Plot 12.0 for analysis considering significant differences in value $P^{*} \leq 0.05, P^{* *} \leq 0.008$, and $P^{* *} \leq 0.005$.

\section{Results}

3.1. MPC in BALB/c Mice. The tumor cells were present in the mesothelium and in nodular whitish tissue from BALB/c oiltreated mice and were identified by the presence of $\mathrm{CD} 138^{+}$ (Figure 1).

\subsection{Th17 and Treg Cells Determination. Treg} $\left(\mathrm{Foxp}^{+} \mathrm{CD}^{+} \mathrm{CD}^{+}\right)$and Th17 $\left(\mathrm{CD}^{+} \mathrm{CD}^{+} \mathrm{IL}^{-17^{+}}\right)$cells were determined by flow cytometry in both strains, seven months after oil induction and in control mice. For Th17 determination the cells were activated with PMA/Ionomycin.
Not activated Th17 cells were reduced in both strains of induced mice (Figures 2(a) and 2(b)), although a higher percentage of Th17 cells was found inthe oil-induced C57BL/6 mice in comparison with oil-induced BALB/c (Figure 2(b)). The differences in Treg cells analyzed at seven months after induction were not significant. However when the induced mice strains were compared, the percentage of Treg cells was higher in BALB/c (Figure 3(b)).

\subsection{B1 Cells Determination. The B1a}

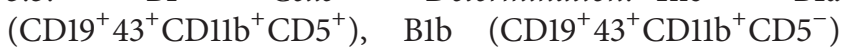
$[19,30,31]$, and $\mathrm{B} 2\left(\mathrm{CD} 19^{+}\right)$cells were determined from the peritoneal contents of both $\mathrm{BALB} / \mathrm{c}$ and $\mathrm{C} 57 \mathrm{BL} / 6$ oil-induced and control mice by flow cytometry at seven months after induction. All B cell populations were diminished in the oil-induced mice in both strains (Figures 4(a) and 4(b)).

3.4. NHC Cells Determination. The NHC (c-kit $\left.{ }^{+}\right)$cells were determined in the mesenteries of BALB/c and C57BL/6 mice at seven months after oil-induction. NHC cells were increased only in oil-induced BALB/c mice (Figures 5(a) and 5(b)).

3.5. Cytokines Determination. IL4, IL-5, IL-9, IL-13, INF$\gamma$, IL-6, IL-10, IL-33, and TGF- $\beta$ were determined in the 


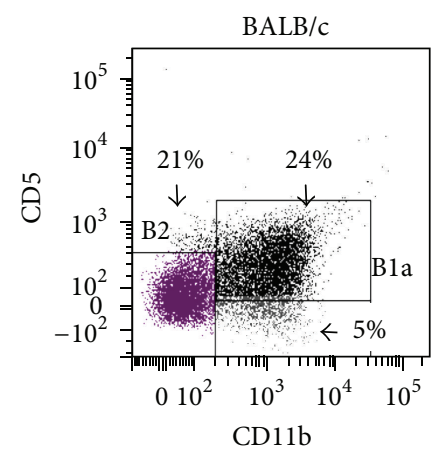

CD11b

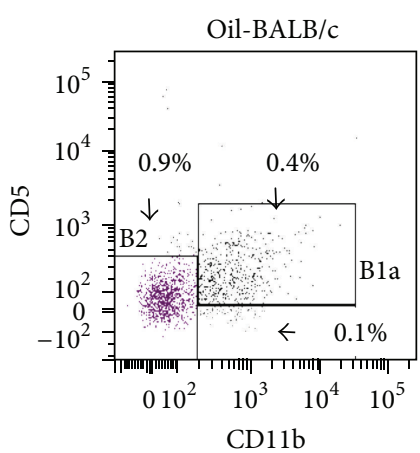

CD11b

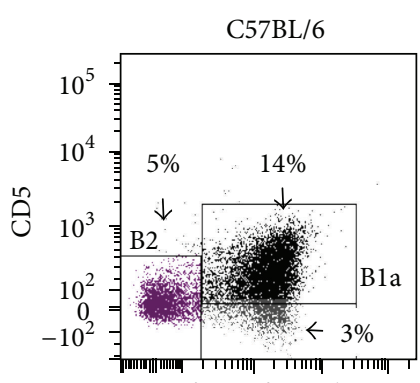

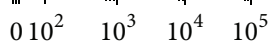

CD11b

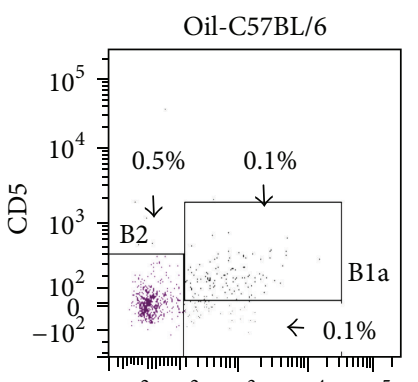

$\begin{array}{llll}-10^{2} 010^{2} & 10^{3} & 10^{4} & 10^{5}\end{array}$

(a)

B1a

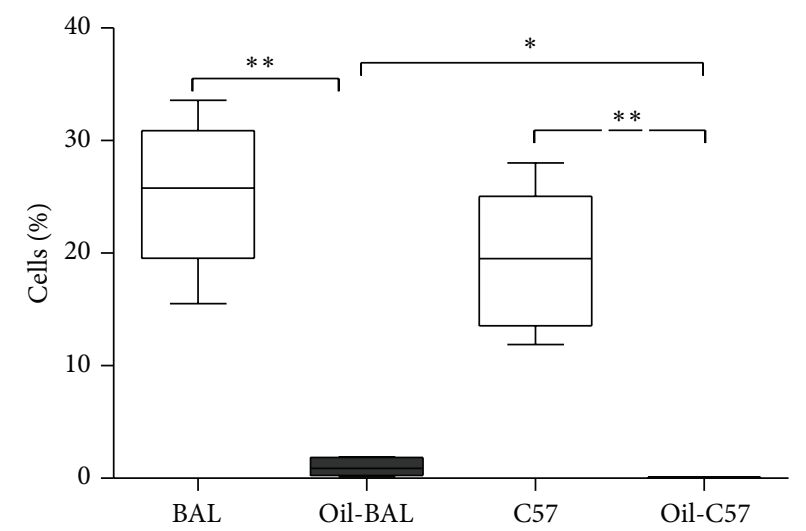

B1b

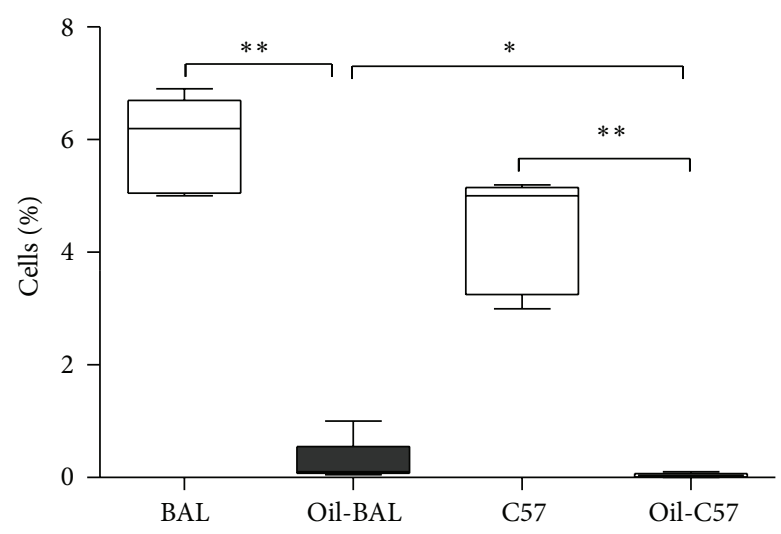

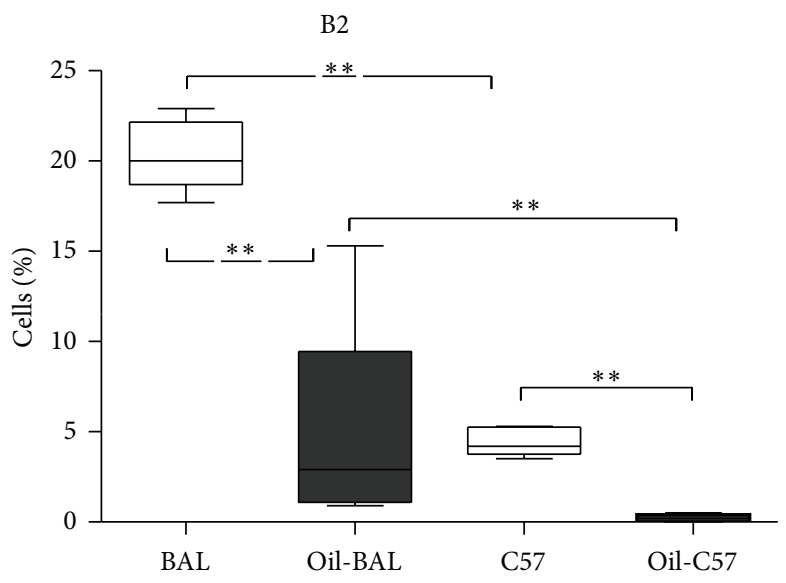

(b)

Figure 4: B2, Bla, and B1b cells. (a) Dot plots show percentages of B cells from the peritoneal content from control and induced mice at seven months after induction of BALB/c and C57BL/6 strains. CD5 ${ }^{-} \mathrm{CD}_{11 \mathrm{~b}^{-}}$(B2 lymphocytes), $\mathrm{CD}^{+} \mathrm{CD}^{\mathrm{B}} \mathrm{b}^{+}$(B1a lymphocytes), and CD5 $5^{-} \mathrm{CD} 11 \mathrm{~b}^{+}$ (B1b lymphocytes) derived from $\mathrm{CD} 19^{+}$selected from total lymphocyte region. (b) Percentage medians of B lymphocytes in the above groups of animals $P^{*} \leq 0.05, P^{* *} \leq 0.008(n=5-10)$. All subpopulations of B lymphocytes of oil-induced animals of both strains are diminished. $\mathrm{BALB} / \mathrm{c}$ oil-induced mice present higher B1a, B1b, and B2 with respect to the $\mathrm{C} 57 \mathrm{BL} / 6$ oil-induced mice. BALB/c control mice show a greater percentage of $\mathrm{B} 2$ with respect to the $\mathrm{C} 57 \mathrm{BL} / 6$ control mice.

peritoneal fluid from both strains at seven months after induction. Table 1 shows no production at all of IL-4, IL-13, and IL-33, whereas IL-9 was equally produced by all groups. INF- $\gamma$, IL-6, and TGF- $\beta$ levels (in green) are increased in oil-induced animals; however, no significant difference was found between $\mathrm{BALB} / \mathrm{c}$ and $\mathrm{C} 57 \mathrm{BL} / 6$ strains.

Only in IL-5 and IL-10 a significant difference between strains was found (Figures 6(a) and 6(b) and Table 1, in pink). 

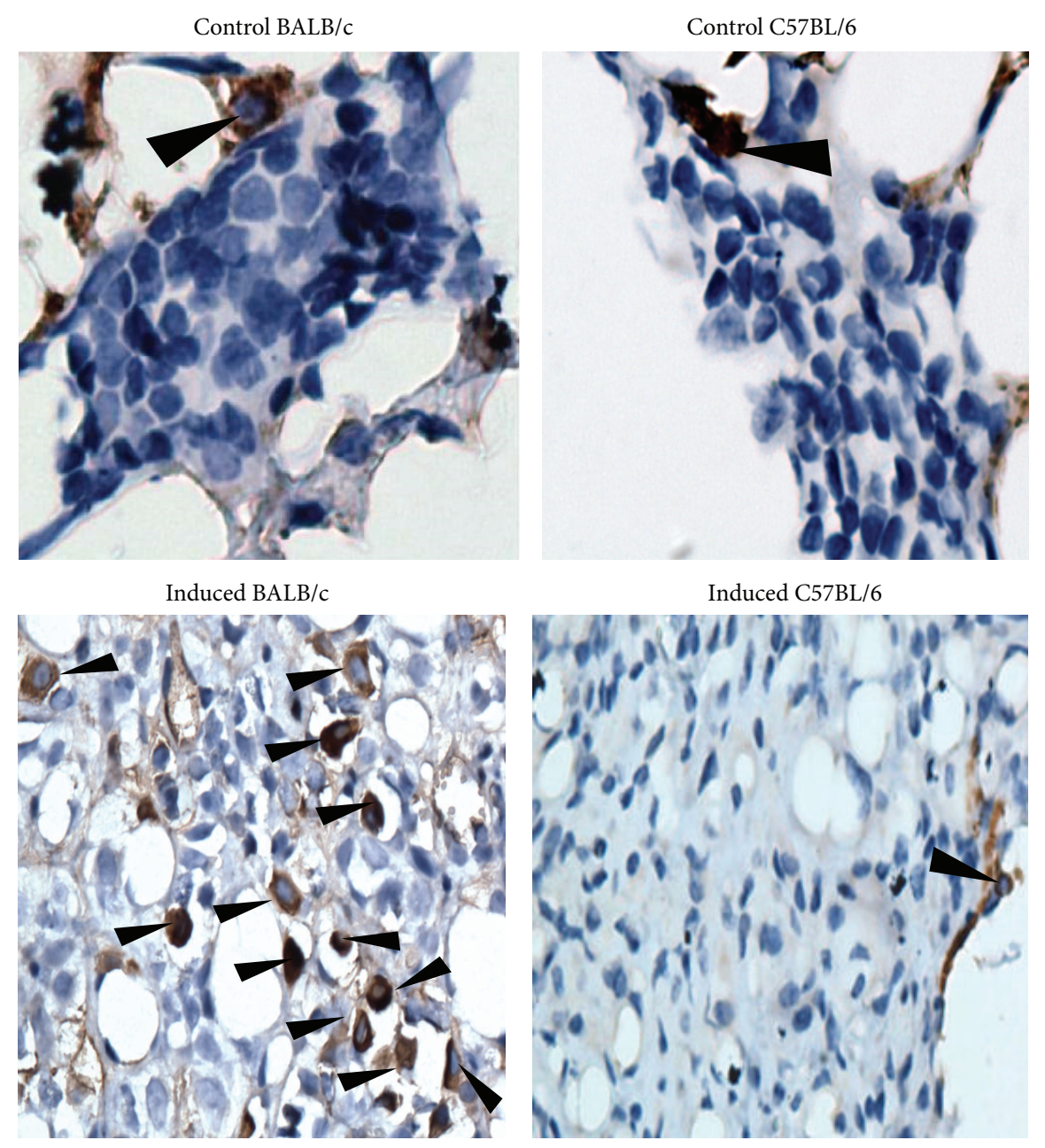

(a)

NHC

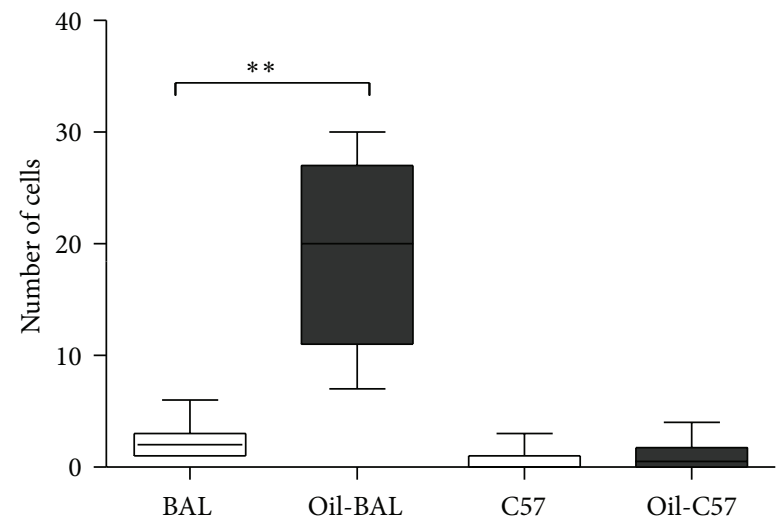

(b)

FIGURE 5: NHC cells. (a) Mesenteric tissue from control and oil-induced mice from both mouse strains at seven months after induction which show c-kit ${ }^{+}$NHC cells (cells with brown tonalities membrane; see arrows), 40x magnification. (b) Medians of number NHC cells $P^{* *} \leq 0.005$ $(n=10)$. Increase of NHC cells was observed only in oil-induced BALB/c mice. 
TABLE 1: Cytokines of peritoneal fluid from mice of both strains BALB/c and C57BL/6, control and induced with pristane, at seven months after induction.

\begin{tabular}{|c|c|c|c|c|}
\hline \multirow{3}{*}{ Cytokines } & \multicolumn{4}{|c|}{ Medians of concentration $(\mathrm{pg} / \mathrm{mL})$} \\
\hline & \multicolumn{2}{|c|}{$\mathrm{BALB} / \mathrm{c}$} & \multicolumn{2}{|c|}{ C57BL/6 } \\
\hline & Control & Oil-induced & Control & Oil-induced \\
\hline IL-4 & 1 & 0 & 0 & 0 \\
\hline IL-13 & 0 & 0 & 0 & 0 \\
\hline IL-33 & 0 & 0 & 0 & 0 \\
\hline IL-9 & 78 & 72 & 73 & 71 \\
\hline$I N F-\gamma$ & 0 & $51^{* *}$ & 0 & $59^{* *}$ \\
\hline$I L-6$ & 0 & $525^{* *}$ & 0 & $314^{* *}$ \\
\hline$T G F-\beta$ & 0 & $1469^{*}$ & 0 & $1408^{*}$ \\
\hline IL-5 & $\mathbf{0}$ & $2^{*}$ & 4 & $43^{* *}$ \\
\hline IL-10 & 544 & 1015 & $4198^{*}$ & 2004 \\
\hline
\end{tabular}

${ }^{*} P \leq 0.05,{ }^{* *} P \leq 0.005(n=10-14)$.

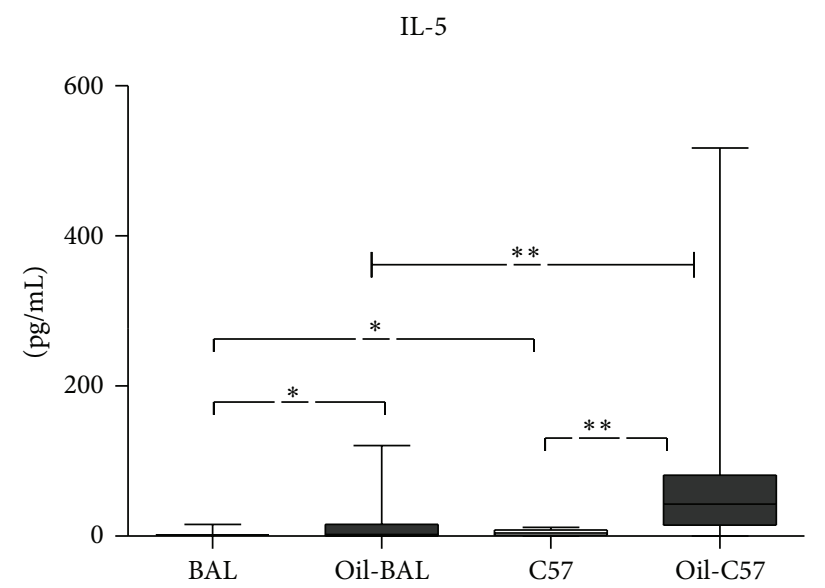

(a)

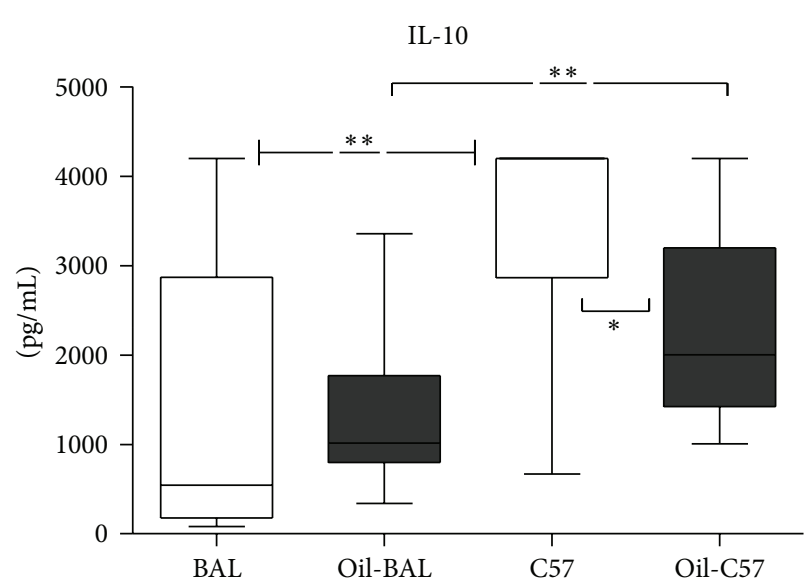

(b)

FIgURE 6: IL-5 and IL-10 cytokines. (a) Concentration medians of IL-5. (b) Concentration medians of IL-10. $P^{*} \leq 0.05, P^{* *} \leq 0.005(n=10-14)$.

An increase of IL-5 was found in oil-induced mice, but the highest concentrations were found in C57BL/6. IL-10 was higher in both control and induced C57BL/6 mice as compared with $\mathrm{BALB} / \mathrm{c}$ mice, despite a decrease of this cytokine in oil-induced C57BL/6 mice, when compared with controls.

\section{Discussion}

It is well known that BALB/c is the only mouse strain sus cep-tible to develop myeloma as result of an inflammatory reaction induced by the intraperitoneal injection of an irritant, usually pristane $[4,29]$.

To try to find out which is the unique characteristic of BALB that allows for the myeloma appearance, we injected pristane in mice of the susceptible BALB/c strain and mice of the not susceptible C57BL/6 strain as control, and determinations of several cells and cytokines were made at seven months after the oil treatment as well as in noninduced control animals.
Both $\mathrm{BALB} / \mathrm{c}$ and $\mathrm{C} 57 \mathrm{BL} / 6$ strains developed a chronic inflammatory process after the pristane treatment. Large lymphocyte infiltrates were observed in the peritoneal content of both induced strains but to a greater degree in BALB/c strain (data not shown).

The appearance of myeloma in $\mathrm{BALB} / \mathrm{c}$ mice was observed seven months after pristane treatment, by the presence of malignant plasma cells with neoplastic morphology and the $\mathrm{CD}_{138^{+}}$marker as has been reported [28].

In this work it was found that the regulation of Th17 and Treg is different between oil-induced BALB/c mice and oilinduced C57BL/6 mice.

Th17 cells of both strains were reduced in oil-induced mice compared to controls, but there were no significant differences between Treg from pristane treated mice and controls, which indicates that the decrease of Th17 is not due to Treg. However when comparing both strains of oilinduced mice, a greater percentage of Treg cells and lower percentage of TH17 cells were observed in the oil-induced $\mathrm{BALB} / \mathrm{c}$ mice, compared to oil-induced C57BL/6 mice which showed inversely proportional values. This would suggest a 
greater effort to try to control the inflammatory process in the BALB/c mouse.

We also found a decrease in subpopulations B1, both B1a and B1b, and B2 lymphocytes in both strains of oil-induced animals, which could be explained by the migration of these cells into other lymphoid compartments. Upon appropriate stimulus, B1 cells in the peritoneal cavity migrate to the mesenteric lymph nodes (MLNs), where they differentiate into antibody-secreting plasma cells $[32,33]$.

Furthermore, the effect of some growth factors generated in the same inflammatory niche and genes of BALB/c mouse as $\mathrm{c}$-myc could influence the evolution of these B lymphocytes to malignant plasma cells [6].

An important difference between the strains was the increase of NHC cells only in BALB/c. Little is known about these cells, but its importance in the innate response has been reported and has been identified as an immunity promoting factor; however recent studies show that they are also involved in tumor formation in immune microenvironments. Bie et al. propose that these cells in peripheral blood are very closely related to an immunosuppressive microenvironment in gastric cancer [34]. This increase in NHC could be an innate response of $\mathrm{BALB} / \mathrm{c}$ mouse for inflammation control; however, the high amount of these cells could influence the development of the myeloma.

Of the studied cytokines, only IL-5 and IL-10 exhibited significant differences between the two strains. The cytokines IL-4, IL-13, IL-33, IL-9, IFN- $\gamma$, IL-6, and TGF- $\beta$ had irrelevant results (Table 1). The cytokines IL-4, IL-13, and IL-33 were not present or their levels were below our detection limits. IL-9 was detected, but no significant differences were found between oil-induced and control animals. Although there are reports of increased levels in pulmonary inflammation [35], IL-9 does not seem of relevance in the peritoneal inflammation.

INF- $\gamma$, IL-6, and TGF- $\beta$ were increased as expected in the inflammation process in the induced animals; however, no differences were found between the strains.

IL-5 level was higher in oil-induced mice of both strains. As the receptor for IL-5 (IL-5R) shares the $\beta$ chain with the GM-CSFR receptor, it can promote lymphopoiesis [36-38] and probably the increase of NHC. However, the increase in IL-5 was higher in C57BL/6 strain which had also higher levels in the control mice.

C57BL/6 showed a high normal level of IL-10 [39] and even after a decrease in the induced C57BL/ 6 the levels of IL10 are still much higher than in the induced BALB/c.

Therefore, the high concentration of IL-10 found in the C57BL/6 mice could prevent the IL-5 induced increase in $\mathrm{NHC}$, thus avoiding the MPC, in contrast with $\mathrm{BALB} / \mathrm{c}$ in which the expansion of NHC lymphocytes could probably drive its development.

Multiple myeloma (MM) is a cancer of plasma cells in humans, and although there have been great strides in recent years in the study of this disease, MM cause remains unknown. Our work in the murine model suggests the involvement of the NHC as an important subject for further research but also as a potential target for an effective therapy.

\section{Conclusions}

The only important difference between the oil-induced inflammatory processes in the two strains is that whereas in the $\mathrm{C} 57 \mathrm{BL} / 6$ mice there is no variation in NHC, these cells are increased in the BALB/c strain, which may be related with the surge of the myeloma.

\section{Conflict of Interests}

The authors declare that they have no conflict of interests with the presented data.

\section{References}

[1] P. N. Anderson and M. Potter, "Induction of plasma cell tumours in BALB-c mice with 2,6,10,14-tetramethylpentadecane (pristane)," Nature, vol. 222, no. 5197, pp. 994-995, 1969.

[2] M. Y. K. Armstrong, P. Ebenstein, W. H. Konigsberg, and F. F. Richards, "Endogenous RNA tumor viruses are activated during chemical induction of murine plasmacytomas," Proceedings of the National Academy of Sciences of the United States of America, vol. 75, no. 9, pp. 4549-4552, 1978.

[3] M. Potter, "A resume of the current status of the development of plasma-cell tumors in mice," Cancer Research, vol. 28, no. 9, pp. 1891-1896, 1968.

[4] M. Potter and C. R. Boyce, "Induction of plasma-cell neoplasms in strain $B A L B / c$ mice with mineral oil and mineral oil adjuvants," Nature, vol. 193, pp. 1086-1087, 1962.

[5] M. Potter and J. S. Wax, "Peritoneal plasmacytomagenesis in mice: comparison of different pristane dose regimens," Journal of the National Cancer Institute, vol. 71, no. 2, pp. 391-395, 1983.

[6] K. Gadó, S. Silva, K. Pálóczi, G. Domján, and A. Falus, "Mouse plasmacytoma: an experimental model of human multiple myeloma," Haematologica, vol. 86, no. 3, pp. 227-236, 2001.

[7] G. Lattanzio, C. Libert, M. Aquilina et al., "Defective development of pristane-oil-induced plasmacytomas in interleukin-6deficient BALB/c mice," American Journal of Pathology, vol. 151, no. 3, pp. 689-696, 1997.

[8] S. Ohno, J.-I. Hayakawa, N. Hashimoto, and F. Wiener, "Murine plasmacytomas, carrier of the $\mathrm{t}(12 ; 15)$ chromosomal translocation, develop from immature/mature B cells not from differentiated plasma cells," Carcinogenesis, vol. 20, no. 4, pp. 529-538, 1999.

[9] Y. K. Lee, R. Mukasa, R. D. Hatton, and C. T. Weaver, "Developmental plasticity of Th17 and Treg cells," Current Opinion in Immunology, vol. 21, no. 3, pp. 274-280, 2009.

[10] S. Romagnani, "Regulation of the T cell response," Clinical and Experimental Allergy, vol. 36, no. 11, pp. 1357-1366, 2006.

[11] H. Jonuleit and E. Schmitt, "The regulator T cell family: distinct subsets and their interrelations," Journal of Immunology, vol.171, no. 12, pp. 6323-6327, 2003.

[12] T. Korn, E. Bettelli, M. Oukka, and V. K. Kuchroo, "IL-17 and Th17 cells," Annual Review of Immunology, vol. 27, pp. 485-517, 2009.

[13] K. Moro, T. Yamada, M. Tanabe et al., "Innate production of $\mathrm{T}_{H} 2$ cytokines by adipose tissue-associated $\mathrm{c}-\mathrm{Kit}^{+} \mathrm{Sca}-1^{+}$lymphoid cells," Nature, vol. 463, no. 7280, pp. 540-544, 2010. 
[14] D. R. Neill, S. H. Wong, A. Bellosi et al., "Nuocytes represent a new innate effector leukocyte that mediates type-2 immunity," Nature, vol. 464, no. 7293, pp. 1367-1370, 2010.

[15] A. E. Price, H.-E. Liang, B. M. Sullivan et al., "Systemically dispersed innate IL-13-expressing cells in type 2 immunity," Proceedings of the National Academy of Sciences of the United States of America, vol. 107, no. 25, pp. 11489-11494, 2010.

[16] S. A. Saenz, M. C. Siracusa, J. G. Perrigoue et al., "IL25 elicits a multipotent progenitor cell population that promotes $\mathrm{T}_{H} 2$ cytokine responses," Nature, vol. 464, no. 7293, pp. 1362-1366, 2010.

[17] Y.-J. Chang, H. Y. Kim, L. A. Albacker et al., "Innate lymphoid cells mediate influenza-induced airway hyper-reactivity independently of adaptive immunity," Nature Immunology, vol. 12, no. 7, pp. 631-638, 2011.

[18] M. C. Amezcua Vesely, M. Schwartz, D. A. Bermejo et al., "FcgammaRIIb and BAFF differentially regulate peritoneal B1 cell survival," The Journal of Immunology, vol. 188, no. 10, pp. 4792-4800, 2012.

[19] F. L. Oliveira, R. Chammas, L. Ricon et al., "Galectin-3 regulates peritoneal B1-cell differentiation into plasma cells," Glycobiology, vol. 19, no. 11, pp. 1248-1258, 2009.

[20] J. W. Tung and L. A. Herzenberg, "Unraveling B-1 progenitors," Current Opinion in Immunology, vol. 19, no. 2, pp. 150-155, 2007.

[21] M. C. Merino and A. Gruppi, "Origin and development of B1 lymphocytes. A cell population involved in defence and autoimmunity," Medicina, vol. 66, no. 2, pp. 165-172, 2006.

[22] S. Garaud, C. le Dantec, A. R. de Mendoza, R. A. Mageed, P. Youinou, and Y. Renaudineau, "IL-10 production by B Cells expressing CD5 with the alternative exon 1B," Annals of the New York Academy of Sciences, vol. 1173, pp. 280-285, 2009.

[23] A. O'Garra and K. Murphy, "Role of cytokines in determining T-lymphocyte function," Current Opinion in Immunology, vol. 6, no. 3, pp. 458-466, 1994.

[24] A. O'Garra and M. Howard, "IL-10 production by CD5 B cells," Annals of the New York Academy of Sciences, vol. 651, pp. 182199, 1992.

[25] D. O. Griffin and T. L. Rothstein, "A small cd11b" human B1 cell subpopulation stimulates T cells and is expanded in lupus," Journal of Experimental Medicine, vol. 208, no. 13, pp. 25912598, 2011.

[26] X. Zhong, W. Gao, N. Degauque et al., "Reciprocal generation of Th1/Th17 and $\mathrm{T}_{\text {reg }}$ cells by B1 and B2 B cells," European Journal of Immunology, vol. 37, no. 9, pp. 2400-2404, 2007.

[27] A. Ray and B. N. Dittel, "Isolation of mouse peritoneal cavity cells," Journal of Visualized Experiments, no. 35, pp. 1-3, 2010.

[28] M. Potter, S. Morrison, F. Wiener, X. K. Zhang, and F. W. Miller, "Induction of plasmacytomas with silicone gel in genetically susceptible strains of mice," Journal of the National Cancer Institute, vol. 86, no. 14, pp. 1058-1065, 1994.

[29] M. Potter and R. C. Maccardle, "histology of developing plasma cell neoplasia induced by mineral oil in Balb/C mice," Journal of the National Cancer Institute, vol. 33, pp. 497-515, 1964.

[30] B. Roy, S. Shukla, M. Łyszkiewicz et al., "Somatic hypermutation in peritoneal B1b cells," Molecular Immunology, vol. 46, no. 8-9, pp. 1613-1619, 2009.

[31] M. Komai-Koma, D. S. Gilchrist, A. N. J. McKenzie, C. S. Goodyear, D. Xu, and F. Y. Liew, "IL-33 activates B1 cells and exacerbates contact sensitivity," Journal of Immunology, vol. 186, no. 4, pp. 2584-2591, 2011.
[32] M. J. Colombo, G. Sun, and K. R. Alugupalli, "T-cell-independent immune responses do not require Cxc ligand 13mediated B1 cell migration," Infection and Immunity, vol. 78, no. 9, pp. 3950-3956, 2010.

[33] S.-A. Ha, M. Tsuji, K. Suzuki et al., "Regulation of B1 cell migration by signals through Toll-like receptors," Journal of Experimental Medicine, vol. 203, no. 11, pp. 2541-2550, 2006.

[34] Q. Bie, P. Zhang, Z. Su et al., "Polarization of ILC2s in peripheral blood might contribute to immunosuppressive microenvironment in patients with gastric cancer," Journal of Immunology Research, vol. 2014, Article ID 923135, 10 pages, 2014.

[35] C. Wilhelm, K. Hirota, B. Stieglitz et al., "An IL-9 fate reporter demonstrates the induction of an innate IL-9 response in lung inflammation," Nature Immunology, vol. 12, no. 11, pp. 1071-1077, 2011.

[36] A. Tominaga, S. Takaki, Y. Hitoshi, and K. Takatsu, "Role of the interleukin 5 receptor system in hematopoiesis: molecular basis for overlapping function of cytokines," BioEssays, vol. 14, no. 8, pp. 527-533, 1992.

[37] K. Takatsu and H. Nakajima, "IL-5 and eosinophilia," Current Opinion in Immunology, vol. 20, no. 3, pp. 288-294, 2008.

[38] S. V. Kaveri, G. J. Silverman, and J. Bayry, "Natural IgM in immune equilibrium and harnessing their therapeutic potential," Journal of Immunology, vol. 188, no. 3, pp. 939-945, 2012.

[39] F. Mion, S. Tonon, B. Toffoletto, D. Cesselli, C. E. Pucillo, and G. Vitale, "IL-10 production by B cells is differentially regulated by immune-mediated and infectious stimuli and requires $\mathrm{p} 38$ activation," Molecular Immunology, vol. 63, no. 2, pp. 606-276, 2015. 


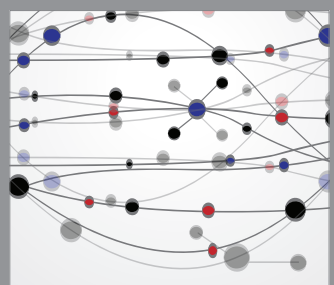

The Scientific World Journal
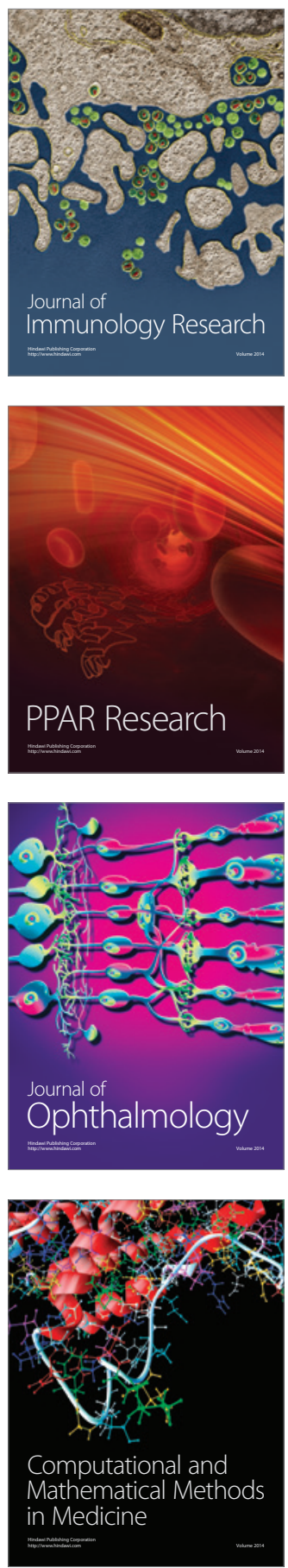

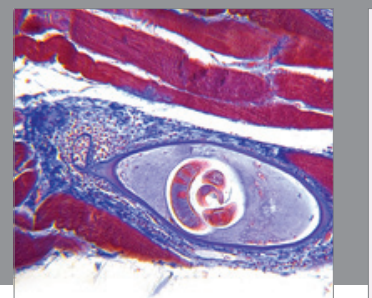

Gastroenterology

Research and Practice
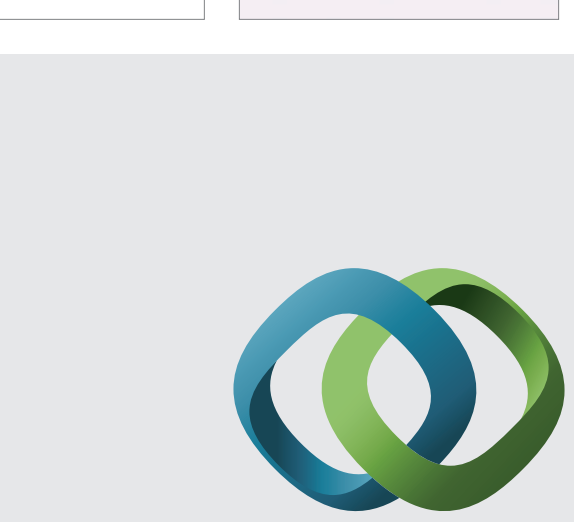

\section{Hindawi}

Submit your manuscripts at

http://www.hindawi.com
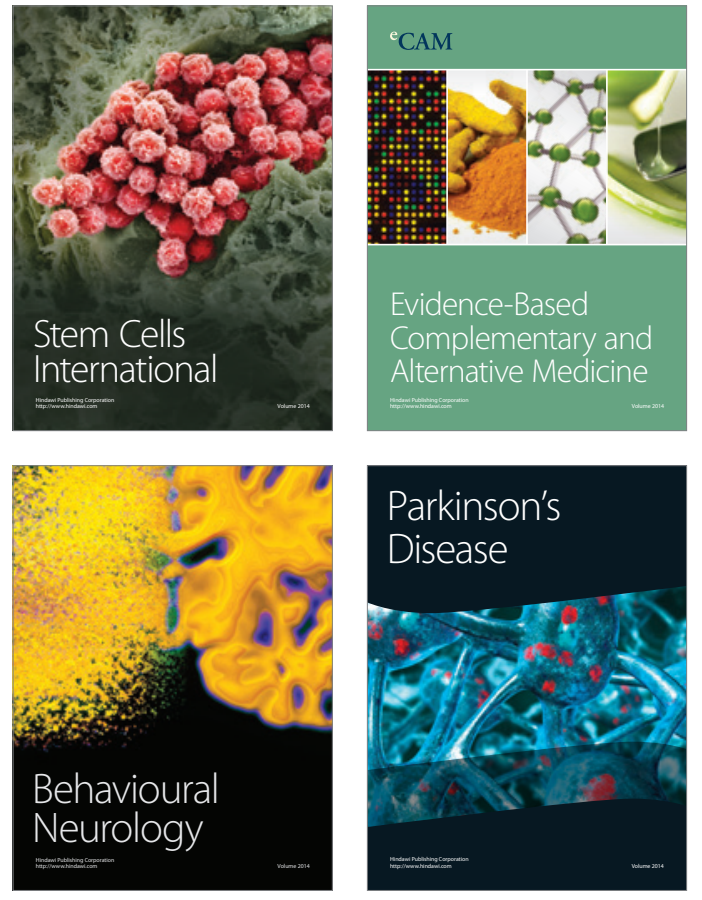
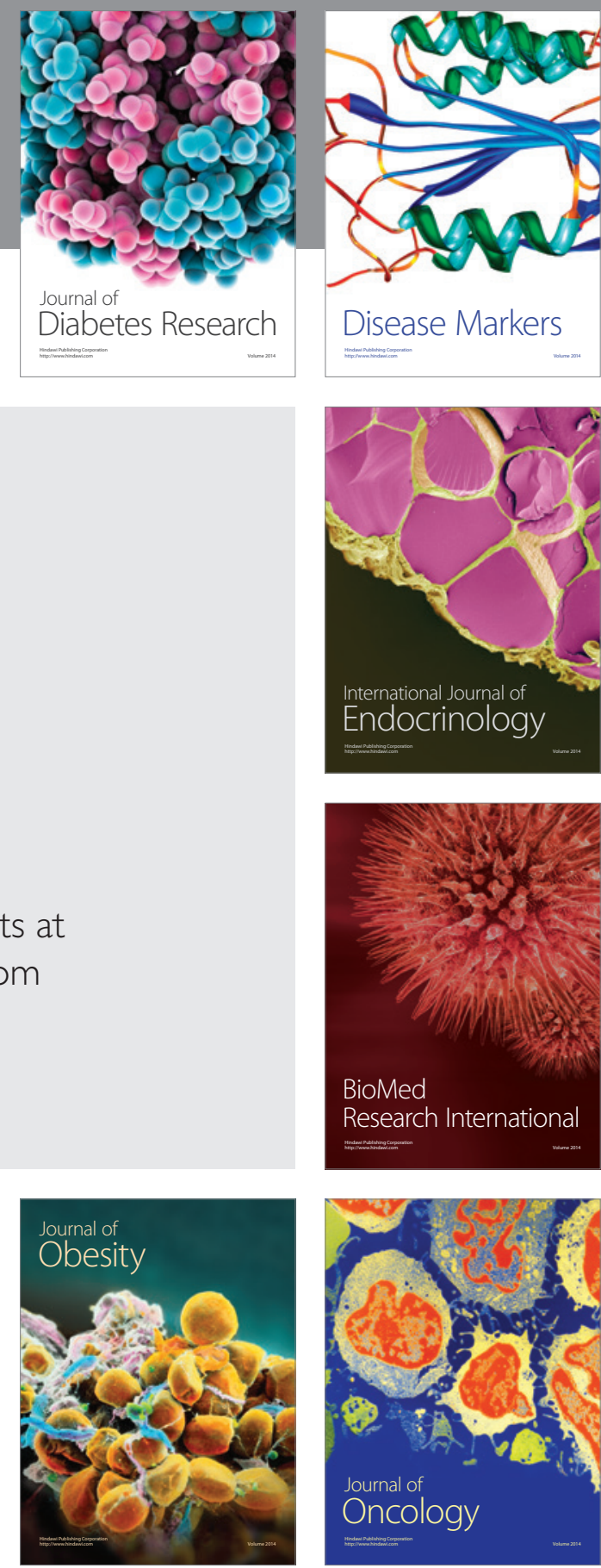

Disease Markers
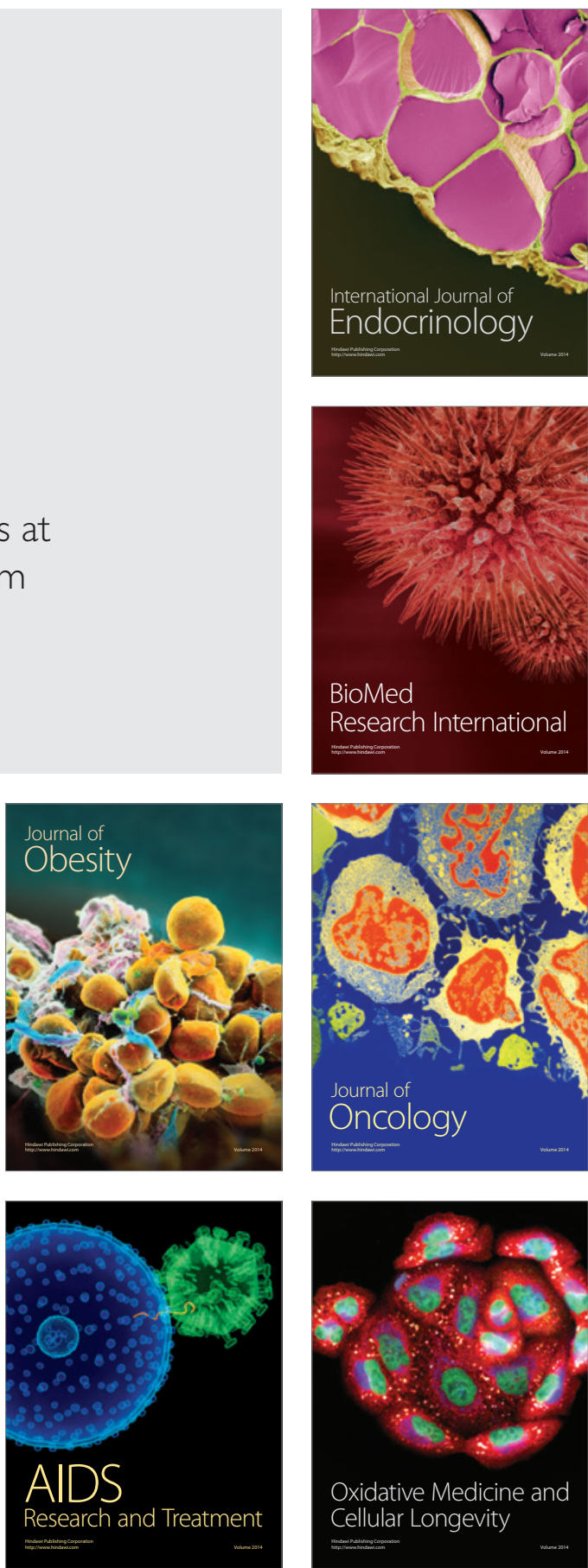